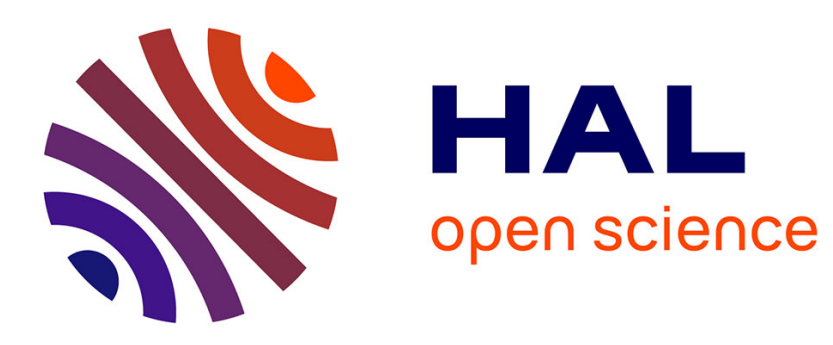

\title{
Halogen bonding effect on electrochemical anion oxidation in ionic liquids $\uparrow$
}

Marie Stacey Alvarez, Cedric Houzé, Sihem Groni, Bernd Schöllhorn, Claire Fave

\section{- To cite this version:}

Marie Stacey Alvarez, Cedric Houzé, Sihem Groni, Bernd Schöllhorn, Claire Fave. Halogen bonding effect on electrochemical anion oxidation in ionic liquids $\dagger$. Organic \& Biomolecular Chemistry, 2021, 10.1039/d1ob01031j . hal-03365384

\section{HAL Id: hal-03365384 \\ https: / hal-univ-paris.archives-ouvertes.fr/hal-03365384}

Submitted on 5 Oct 2021

HAL is a multi-disciplinary open access archive for the deposit and dissemination of scientific research documents, whether they are published or not. The documents may come from teaching and research institutions in France or abroad, or from public or private research centers.
L'archive ouverte pluridisciplinaire HAL, est destinée au dépôt et à la diffusion de documents scientifiques de niveau recherche, publiés ou non, émanant des établissements d'enseignement et de recherche français ou étrangers, des laboratoires publics ou privés. 


\title{
Halogen bonding effect on electrochemical anion oxidation in ionic liquids $\uparrow$
}

\author{
Marie Stacey Alvarez, (iD Cedric Houzé, Sihem Groni, (iD) Bernd Schöllhorn (iD * and \\ Claire Fave (iD) *
}

Three Ionic liquids (ILs) based on an imidazolium core have been compared and used as solvents for the oxidation of various anions. Electrochemical experiments as well as NMR titrations and X-ray diffraction analyses unambiguously confirm the crucial role of non-covalent halogen bonding on the oxidation potentials and consequently the electrochemical window of the respective ILs.

\section{Introduction}

Non-covalent interactions are always important in solution chemistry and often determine kinetics and thermodynamics of supramolecular assemblies and chemical reactions, whether in the domain of molecular recognition, self-assembly, covalent bond activation or catalysis. ${ }^{1}$

Sigma-hole bonding is one of the most recently established concepts of non-covalent bonds among which Halogen bonding (XB) has seen an upsurge of interest by the scientific community. Nowadays it is recognized as an important tool in supramolecular chemistry. ${ }^{2}$ According to the IUPAC definition $\mathrm{XB}$ occurs when there is a net attractive interaction between the electrophilic region ( $\sigma$-hole) of a halogen atom (XB-donor) and a nucleophilic region of a Lewis base (XB-acceptor). ${ }^{3}$ Only recently, it has been demonstrated how electrochemistry can be used to detect and to control $\mathrm{XB}$ in solution ${ }^{4}$ and on surface-confined systems. ${ }^{5}$ The strength of a redox active XBdonor or acceptor can be tuned by changing its charge via an electrochemical reaction which can be fully reversible. The electrochemical controlling and probing of $\mathrm{XB}$ is an essential tool to better understand supramolecular properties and reactivity in complex systems involving multiple competing noncovalent interactions. ${ }^{6}$
Today there is a considerable interest in ionic liquids (ILs) for possessing particular properties such as low volatility, high polarity, good electric conductivity and large potential windows. ${ }^{7}$ Since the early 2000 s, ILs are used in many applications concerning various domains such as lithium-ion batteries, solar cells, fuel cells, organic synthesis, homogeneous catalysis and extraction procedures. ${ }^{8}$ A simple definition can describe ILs as salts with low melting points below $100{ }^{\circ} \mathrm{C}$.

Certain properties of ILs make them particularly interesting for electrochemical studies. ${ }^{9}$ An interesting aspect is the possibility of facile chemical engineering the organic cations combined with varying anions, in order to tune the resulting properties. In fact, minor changes of the molecular structure can induce drastic changes of the physical properties.

For instance, the group of Strassner ${ }^{10}$ has reported on of the widest electrochemical window (EW) reported in ILs on a GC electrode for imidazolium derivatives by changing the anion $\left(\mathrm{EW}=3.77 \mathrm{~V}\right.$ with $\mathrm{NTf}_{2}{ }^{-}$vs. $\mathrm{EW}=7.17 \mathrm{~V}$ with $\left.\mathrm{N}(\mathrm{CN})_{2}{ }^{-}\right)$. Viscosity, a key parameter in low melting ionic liquids is also mainly influenced by chemical modification of the cation due to the presence of weak interactions such as Hydrogen bonding or Van de Waals interactions. ${ }^{11}$ However, rationalization of the structure/properties relationship is not straightforward and prediction often not possible. Recently, some groups have reported on the impact of $\mathrm{XB}$ on ILs properties or applications. $^{12}$

In this work the electrochemical detection of XB in ILs is described for the first time. Electrochemical methods allowed us to investigate the effect of non-covalent $\mathrm{XB}$ on the reactivity of Lewis basic anions depending on the nature of the ionic liquid cation. The experiments revealed a significant influence of predominant non-covalent interactions on the electrochemical halide oxidation, consequently impacting the width of the electrochemical windows.

We focused on low melting ionic liquids possessing imidazolium cations and bistriflimide anions (or bis(trifluoromethane) sulfonimide or $\mathrm{NTf}_{2}^{-}$). The choice of the anion was guided by its intrinsic hydrophobic character and its low Lewis basicity which 
should attenuate competition with others LB. ${ }^{11 a, 13}$ The imidazolium core is a commonly used cation of many already reported ILs and chemical modification is rather straight forward. In this comparative study three ILs were used, only differing in the nature of the substituent in the $\mathrm{C} 2$ position of the respective imidazolium cation: $\mathrm{H}$ (H-IL), $\mathrm{CH}_{3}$ (Me-IL) and I (I-IL) (Scheme 1).

\section{Results and discussion}

Three imidazolium derivatives H-IL, Me-IL and I-IL have been studied. H-IL and Me-IL were obtained after metathesis reaction (Scheme 2) of $\mathbf{1}$ and 2, respectively, with bis(trifluoromethane)sulfonimide lithium salt (LiTFSI). ${ }^{14}$ In order to access the 1-ethyl-2-iodo-3-methylimidazolium bis (trifluorométhane)sulfonimide I-IL a multiple step synthesis was necessary. First, deprotonation of 1-ethyl-imidazole 3 follow by iodination gave 4 in $72 \%$ yield. ${ }^{15}$ Selective methylation in presence of methyl trifluoromethanesulfonate ${ }^{16}$ in acetonitrile at $0{ }^{\circ} \mathrm{C}$ afford after 12 hours the imidazolium derivative $\mathbf{5}$ with triflate as counter anion. Finally, I-IL was obtained by classic metathesis with LiTFSI in water. The three derivatives have been fully characterized by ${ }^{1} \mathrm{H},{ }^{13} \mathrm{C}$ and ${ }^{19} \mathrm{~F}$ NMR spectroscopy (Fig. S1, S2, and S3 $\dagger$ ) and the obtained data are in agreement with similar derivatives described in the literature. ${ }^{17}$ The absence of iodide anions (for I-IL see Fig. S12†) and the low water content of less than $0.5 \%$ (Fig. S4†) of the

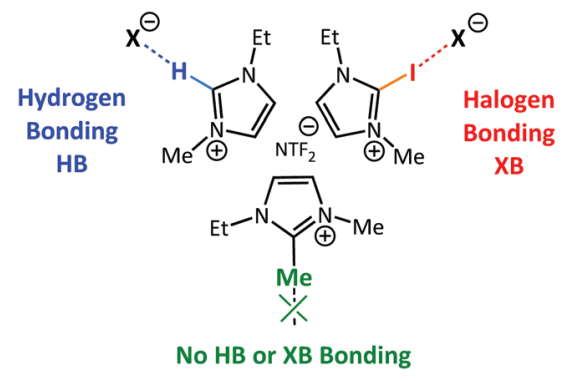

$\mathrm{X}=$ Lewis Base

Scheme 1 Description of RTILs and the associated non-covalent intermolecular interactions.

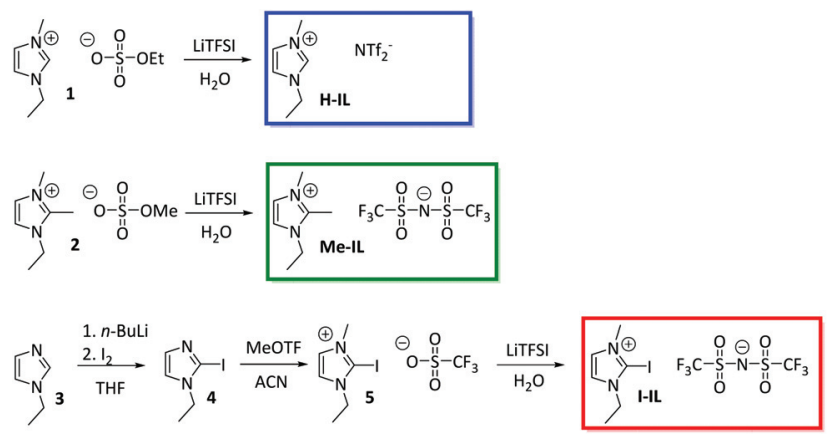

Scheme 2 Synthesis of the ILs derivatives.
Table 1 Physicochemical properties determined for $\mathrm{H}-\mathrm{IL}, \mathrm{Me}-\mathrm{IL}$, and I-IL

\begin{tabular}{llll}
\hline & Me-IL & H-IL & I-IL \\
\hline$m_{p^{p}}{ }^{a}$ & $22-25$ & nd & $53-57$ \\
$\eta^{c}$ & $93 \pm 0.9$ & $27 \pm 0.2$ & $48 \pm 0.7$ \\
$\sigma^{c}$ & $1.68 \pm 0.18$ & $1.89 \pm 0.16$ & $0.34 \pm 0.04$ \\
$\rho^{d}$ & $1.49 \pm 0.01$ & $1.52 \pm 0.03$ & $1.58 \pm 0.05$ \\
$M^{e}$ & 405.3 & 391.3 & 517.2 \\
$C_{\mathrm{n}}{ }^{f}$ & $3.51 \pm 0.03$ & $3.88 \pm 0.11$ & $3.06 \pm 0.13$ \\
$D^{g}$ & $5.15 \pm 0.05$ & $17.7 \pm 0.16$ & $10.6 \pm 0.15$
\end{tabular}

${ }^{a}$ Melting point in ${ }^{\circ} \mathrm{C} .{ }^{b}$ Dynamic viscosity in mPa s. ${ }^{c}$ Conductivity at $40{ }^{\circ} \mathrm{C}$ for $\mathbf{H}$-IL and Me-IL and $60{ }^{\circ} \mathrm{C}$ for I-IL in S m${ }^{-1} .{ }^{d}$ Density in $\mathrm{g}$ $\mathrm{ml}^{-1}$. ${ }^{e}$ Molar mass in $\mathrm{g} \mathrm{mol}{ }^{-1} .{ }^{f}$ Molar concentration in $\mathrm{mol} \mathrm{L}^{-1}$. ${ }^{g}$ Diffusion coefficient in $10^{-8} \mathrm{~cm}^{2} \mathrm{~s}^{-1}$ measured at $40{ }^{\circ} \mathrm{C}$ for $\mathbf{H}-\mathbf{I L}$ and Me-IL and at $60^{\circ} \mathrm{C}$ for I-IL. nd = non determined.

prepared compounds were confirmed by NMR spectroscopy and cyclic voltammetry.

The effect of the nature of the substituent in the $\mathrm{C} 2$ position of the imidazolium core on important physical properties has been studied for H-IL, Me-IL and I-IL (Table 1).

Electrochemical experiments provide an estimate of the relative viscosity via the determination of the diffusion coefficient $(D)$. We have thus recorded cyclic voltammograms (CVs) of decamethylferrocene ( $\mathrm{dmfc})$ in the three ILs and then performed chronoamperometry (Fig. S5-S7†). ${ }^{18}$

The Cottrell ${ }^{19}$ equation allows to calculate the $D$ values in Me-IL $\left(5.15 \times 10^{-8}\right)$, H-IL $\left(1.77 \times 10^{-7}\right)$, and I-IL $\left(1.06 \times 10^{-7}\right.$ $\left.\mathrm{cm}^{2} \mathrm{~s}^{-1}\right)$.

The data of Me-IL and H-IL are in agreement with literature values ${ }^{20}$ being $2-3$ orders of magnitude smaller than those of conventional organic solvents. They are in accordance with the respective viscosities of the ILs. Besides purely electrostatic interactions between the different imidazolium cations and the counterion $\mathrm{NTf}_{2}{ }^{-}$the influence of Hydrogen bonding (HB) and $\mathrm{XB}$ can be considered in order to explain the determined properties. $^{21}$

Compared to H-IL the viscosity of the methylated compound Me-IL is considerably higher despite its weaker HB donor properties (Table 1). This counterintuitive phenomenon can be explained by a lower degree of freedom for the $\mathrm{N}$-substituted alkyl chains in Me-IL, leading to a more densely packed and viscous liquid. ${ }^{22}$ When comparing H-IL and I-IL the higher density and lower diffusion coefficient of the latter suggest $\mathrm{XB}$ interactions with the counterions, stronger than the present HB. Because of the strong temperature dependence of the physical properties of ILs, all following electrochemical experiments have been conducted under thermostatic control. Before investigating the electrochemical properties of the pure ILs the three compounds H-IL, Me-IL and I-IL have been used as supporting electrolyte salts at a $0.1 \mathrm{M}$ concentration in DMF. The CVs (Fig. S8 $\dagger$ ) show similar irreversible oxidation waves for all systems of over $1.1 \mathrm{~V}$, merging with the electrochemical window limit. The cathodic potential limits are different for each compound with the earliest reduction poten- 
tial for I-IL at $-0.5 \mathrm{~V}$ which can be attributed to $\mathrm{C}-\mathrm{I}$ bond reduction (Fig. S9†).

Chloride has been described to be a strong XB acceptor. In $0.1 \mathrm{M} \mathrm{TBAPF}_{6} / \mathrm{DMF}$, it can be irreversibly oxidized at $+1.1 \mathrm{~V} v s$. SCE.

The oxidation peak potentials of chloride (TBACl) in $0.1 \mathrm{M}$ H-IL/DMF and Me-IL/DMF do not change significantly (Fig. S29†) compared to the standard electrolyte 0.1 $\mathrm{M} \mathrm{TBAPF}_{6} /$ DMF, suggesting that potential $\mathrm{HB}$ or $\pi$-anion interactions were negligible. When using I-IL as supporting electrolyte a large peak potential shift $\Delta E_{\mathrm{p}}^{\mathrm{Ox}}\left(\mathrm{Cl}^{-}\right)$of about $109 \mathrm{mV}$ was measured (Fig. S29 $\dagger$ ). This behaviour was attributed to the formation of an XB complex between the XB-acceptor $\mathrm{Cl}^{-}$and the donor I-IL. The electron withdrawing effect iodo-imidazolium cation renders the oxidation of the stabilized complex more difficult.

The affinity constants between halide anions and the ILs cations were determined by ${ }^{1} \mathrm{H}$ NMR spectroscopy. $1 \mathrm{mM}$ solutions of H-IL, Me-IL or I-IL in DMSO were titrated with increasing concentrations of chloride, bromide, iodide, nitrate and nitrophenolate (all the details are given in the ESI $\dagger$ ). ${ }^{1} \mathrm{H}$ NMR spectra of the chloride titration of I-IL are shown in Fig. 1 (and Fig. S19 and S20 ). Upon the addition of 100 equivalents of chloride the signal of the $\mathrm{H}_{\mathrm{B}}$-proton on the imidazolium core was progressively shifting from 7.975 to 7.840 ppm (Fig. 1 and Table S2 $\dagger$ ). The corresponding association constants were determined by using the BindFit ${ }^{23}$ online program assuming a predominant $1: 1$ stoichiometry (Table 2 and Fig. 2).

In the case of I-IL the highest association constant was found for chloride (119 $\mathrm{M}^{-1}$ ) compared to the weaker LBs iodide $\left(K_{\mathrm{a}}=51 \mathrm{M}^{-1}\right)$ and nitrophenolate $\left(K_{\mathrm{a}}=19 \mathrm{M}^{-1}\right)$. For nitrate no significant binding $\left(K_{\mathrm{a}}=7 \mathrm{M}^{-1}\right)$ was observed, taking into account an uncertainty of $\pm 5 \mathrm{M}^{-1}$ (Table 2). These results follow the classic trend of the increasing XB-acceptor strength except for bromide with $K_{\mathrm{a}}=183 \mathrm{M}^{-1}$. The peculiar behaviour for bromide has not been yet elucidated in our case but previous data have already reported higher affinity toward bromide than chloride in the case of iodo-imidazolium XBdonor. $^{24}$ As expected, the affinity constants measured for chloride towards H-IL or Me-IL, respectively afforded smaller

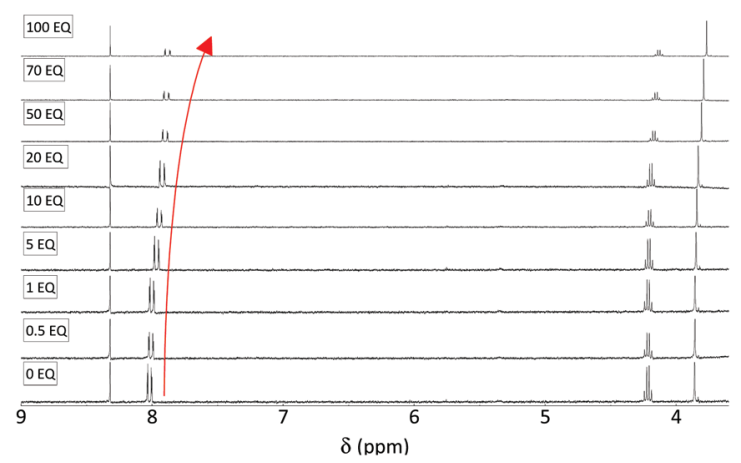

Fig. $1{ }^{1} \mathrm{H}$ NMR spectra of the chloride titration of I-IL in DMSO. The red trace indicates the shift of the signals of interest $\left(\mathrm{H}_{\mathrm{B}}\right)$.
Table 2 Affinity constants for the anion binding titration with IL by ${ }^{1} \mathrm{H}$ NMR following the $\mathrm{H}$ on the imidazolium core in DMSO-d6

\begin{tabular}{llll}
\hline & H-IL & Me-IL & I-IL \\
\hline $\mathrm{Cl}^{-}$ & $2 \pm 0.1^{a}$ & $6 \pm 2^{a}$ & $119 \pm 11^{a}$ \\
$\mathrm{Br}^{-}$ & $-{ }^{b}$ & $-{ }^{b}$ & $183 \pm 9^{a}$ \\
$\mathrm{I}^{-}$ & $-{ }^{b}$ & $-{ }^{b}$ & $51 \pm 7^{a}$ \\
$\mathrm{NO}_{3}{ }^{-}$ & $-{ }^{b}$ & $-{ }^{b}$ & $\mathrm{nd}^{c}$ \\
$\mathrm{NO}_{2} \mathrm{PhO}^{-}$ & & & $19 \pm 6^{a}$
\end{tabular}

${ }^{a}$ Affinity constant calculated by bindfit $\left(\mathrm{M}^{-1}\right) .{ }^{b}$ Not conducted. ${ }^{c}$ Value too small to be measured with a reasonable margin of error.

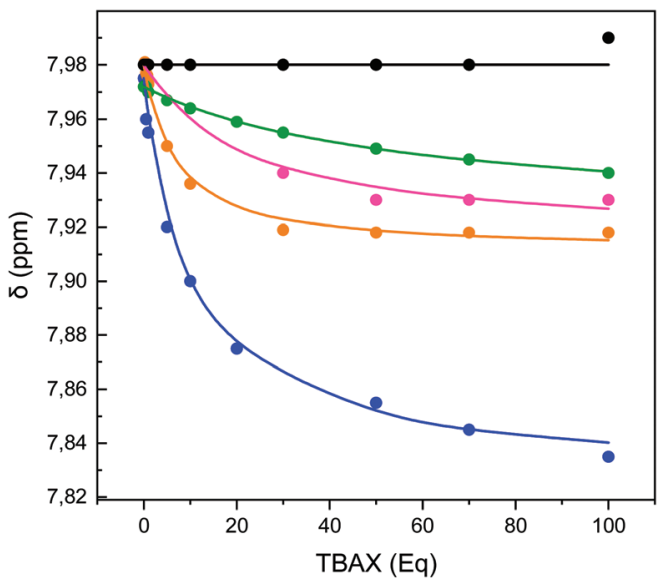

Fig. 2 Anion binding titration with I-IL by ${ }^{1} \mathrm{H}$ NMR following the $\mathrm{H}$ on the imidazolium core in DMSO-d6: experimental titration data (circles) with fitted binding (lines). Chloride in blue, bromide in orange, iodide in pink, nitrophenolate in green and nitrate in black.

values (Fig. S15 to S18 and Table S2†) confirming our hypothesis of the predominance of $\mathrm{XB}$ interactions among the other potential weak interactions such as $\mathrm{HB}$ or $\pi$-anion interactions in the studied system.

These results are in accordance with data of similar 2-iodoimidazolium cations and halides $\left(K_{\mathrm{a}}\right.$ of $150 \mathrm{M}^{-1},{ }^{1} \mathrm{H}$ NMR in DMSO) previously reported in the literature by Resnati and coworkers. $^{25}$

It is noteworthy that also in this case $\mathrm{XB}$ was stronger than HB. The formation of XB complexes could also be also confirmed via X-ray single crystal structure analysis (Fig. 3). Crystals of $\left[\mathbf{I}-\mathbf{I L}, \mathbf{I}^{-}, \mathbf{I}_{\mathbf{3}}{ }^{-}\right]$and $\left[\mathbf{I}-\mathbf{I L}, \mathbf{B r}^{-}\right]$were obtained by slow diffusion of a solution of TBAX $(0.25 \mathrm{M})$ in isopropanol into a solution of I-IL $(0.25 \mathrm{mM})$ in $n$-hexane. The interatomic distance between $\mathbf{I}-\mathbf{I L}$ and $\mathrm{I}^{-}$or $\mathrm{Br}^{-}$are significantly shorter than the sum of the respective van der Waals radii (Table 3). Furthermore, the $\mathrm{C}-\mathrm{X} \cdots \mathrm{X}$-angles are close to linearity, clearly suggesting directional halogen bonding.

These results are in agreement with the structures reported for other iodo-imidazolium derivatives with halide counter ions. $^{24,26,27}$

All the above results have clearly shown that $\mathbf{I}-\mathbf{I L}$ acts as a powerful XB-donor for halide anions whether in solution in an 


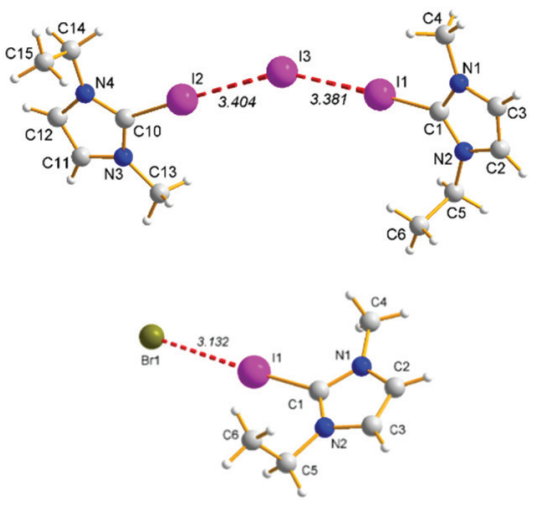

Fig. 3 Crystal structures of [I-II, $\left.I^{-}\right]$and [I-II, $\left.\mathrm{Br}^{-}\right]$.

Table 3 Halogen bond geometry in the crystal structure of compounds [I-IL, $\left.\mathrm{I}^{-}\right]$and $\left[\mathrm{I}-\mathrm{IL}, \mathrm{Br}^{-}\right]$: inter atomic distances $(d)$ and angles $(\angle)$

\begin{tabular}{llllll}
\hline & $\mathrm{C}-\mathrm{I} \cdots \mathrm{X}$ & $d_{\mathrm{I} \cdots \mathrm{X}}{ }^{a}[\AA]$ & Ratio of $r_{\mathrm{vdW}}{ }^{b}$ & $L_{\mathrm{C}-\mathrm{I} \cdots \mathrm{X}}\left[{ }^{\circ}\right]$ & $d_{\mathrm{C} \cdots \mathrm{X}}{ }^{a}[\AA]$ \\
\hline$\left[\mathbf{I}-\mathrm{IL}, \mathbf{I}^{-}\right]$ & $\mathrm{C} 1-\mathrm{I} 1 \cdots \mathrm{I} 3$ & $3.3814(5)$ & $85 \%$ & $177.8(1)$ & $2.074(4)$ \\
& $\mathrm{C} 10-\mathrm{I} 2 \cdots \mathrm{I} 3$ & $3.4044(5)$ & $86 \%$ & $175.1(1)$ & $2.075(4)$ \\
{$\left[\mathbf{I}-\mathrm{IL}, \mathbf{B r}^{-}\right]$} & $\mathrm{C} 1-\mathrm{I} 1 \cdots \mathrm{Br} 1$ & $3.1320(4)$ & $82 \%$ & $171.39(8)$ & $2.086(3)$ \\
${ }^{a} \mathrm{In} \AA^{b}{ }^{b}$ Ratio of $d_{\mathrm{I} \cdots \mathrm{x}}$ and the theoretical $\sum r_{\mathrm{vdW}}$ of I and X.
\end{tabular}

organic solvent (NMR, Electrochemistry) or in the solid state (X-ray analysis).

Based on this evidence, we have studied the oxidation of anionic LB in pure ILs by cyclic voltammetry (CV) in the presence of either decamethylferrocene ( $\mathrm{dmfc}$ ) or ferrocene $(\mathrm{Fc})$ as internal standards. In solution, the two Fc derivatives showed a reproducible standard potential difference $\Delta\left(E_{\mathrm{dmfc}}^{\circ \prime}-E_{\mathrm{Fc}}^{\circ \prime}\right)$ of $-514 \mathrm{mV}$ (Fig. S11†) in the presence of both, I-IL or Me-IL. In the following experiments, all redox potential values are reported $v s . \mathrm{Fc} / \mathrm{Fc}^{+}$. The experiments in the ILs have been performed either at $40{ }^{\circ} \mathrm{C}$ for $\mathbf{H}$-IL and Me-IL or at $60{ }^{\circ} \mathrm{C}$ for I-IL to due to solubility issues (Fig. 4). However, CV at various

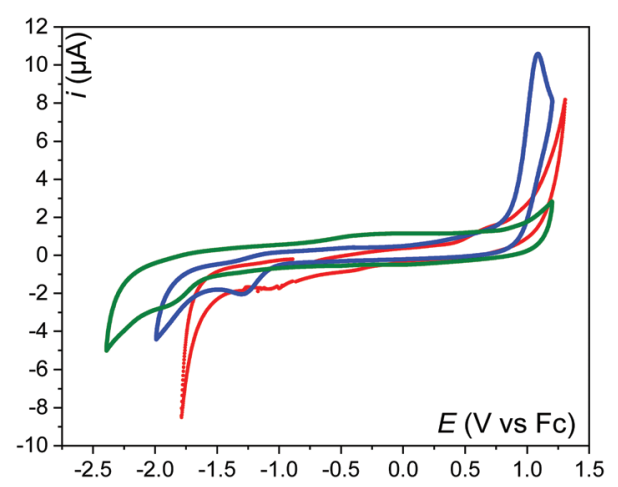

Fig. $4 \mathrm{CV}$ on glassy carbon electrode in pure ionic liquids vs. $\mathrm{Fc} / \mathrm{Fc}^{+}$, $\mathrm{H}$-IL (blue trace), Me-IL (green trace) and I-IL (red trace). $T=40{ }^{\circ} \mathrm{C}$ for $\mathrm{Me}-\mathrm{IL}$ and $\mathrm{H}-\mathrm{Il}$ and $T=60^{\circ} \mathrm{C}$ for I-IL; $\nu=0.1 \mathrm{~V} \mathrm{~s}^{-1}$. temperature (from 30 to $60{ }^{\circ} \mathrm{C}$ ) have been performed in the case of Me-IL (Fig. S37†) for easier comparing the 3 ILs.

The pure ionic liquids Me-IL (Fig. 4) exhibits a large potential window from $-2.5 \mathrm{~V}$ to $+1.5 \mathrm{~V}$. In the case or I-IL, an early reduction wave starting at $-1 \mathrm{~V}$ can be again attributed to the irreversible reductive cleavage of the C-I bond (Fig. S9†).

Based on theoretical calculations ${ }^{22}$ and our experimental results concerning ILs as supporting electrolyte salts we used Me-IL as our reference system, lacking strong HB or XB.

In the electrochemical study of halide oxidation in the pure ILs the measured peak current was normalized in order to get rid of viscosity variations of the three RTILs. The $\mathrm{CV}$ of $\mathrm{Cl}^{-}$in Me-IL (green trace in Fig. 5) exhibits a quasi-reversible wave with a $E_{\mathrm{pOx}}$ (Me-IL) of $0.87 \mathrm{~V}$ with partial formation of $\mathrm{Cl}_{2}$.

A similar behaviour was observed for H-IL with $E_{\mathrm{pOx}}$ (H-IL) $=0.82 \mathrm{~V} v s . \mathrm{Fc} / \mathrm{Fc}^{+}$(blue trace in Fig. 5). In contrast, the $\mathrm{CV}$ recorded in pure I-IL presents a considerably higher $E_{\mathrm{pOx}}(\mathbf{I}-\mathbf{I L})$ of $1.48 \mathrm{~V} v s . \mathrm{Fc} / \mathrm{Fc}^{+}$(Table 4 ).

The variation of $\Delta E_{\mathrm{pOx}}$ between Me-IL and H-IL or I-IL $\left(\Delta E_{\mathrm{pOx}}=E_{\mathrm{pOx}}(\mathbf{I}-\mathrm{IL})-E_{\mathrm{pOx}}(\mathbf{M e}-\mathbf{I L})\right)$ is a good indicator of the impact of $\mathrm{HB}$ or $\mathrm{XB}$ interactions on oxidation of anion XBacceptors. Oxidation of chloride in I-IL leads to $\Delta E_{\mathrm{pOx}}=$ $608 \mathrm{mV}$ and in H-IL to $\Delta E_{\mathrm{pOx}}=-48 \mathrm{mV}$ indicating a strong influence of XB compared to HB. The high $\Delta E_{\mathrm{pOx}}$ in I-IL can be attributed to strong $\mathrm{XB}$, stabilizing the anion.

However, we still cannot explain the negative peak potential shift in the case of H-IL. Even weak HB should have a stabilizing effect. Conclusively the particular properties of $\mathbf{M e - I L},{ }^{22}$ discussed above, could be responsible for the observed behaviour.

Traces of $\mathrm{H}_{2} \mathrm{O}$ in ILs could affect their properties and in particular the electrochemical windows. ${ }^{28}$ Small quantities of water (from $0.2 \%$ up to $2 \% \mathrm{wt}$ ) were added to the studied ILs. However, in all ILs no significant potential shift for the chloride oxidation could be detected (Fig. S34 to 36†).

Similar trends were observed in I-IL for bromide and iodide with $\Delta E_{\mathrm{pOx}}$ being $533 \mathrm{mV}$ and $371 \mathrm{mV}$, respectively (Table 4

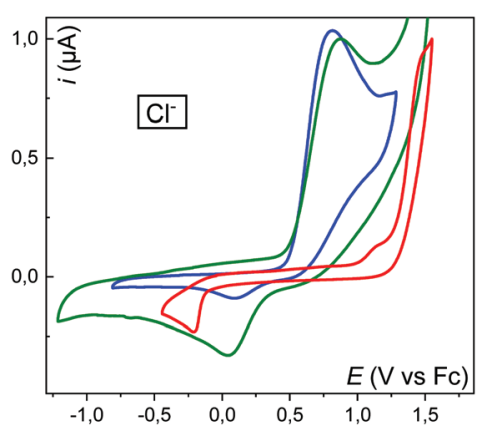

Fig. 5 Normalised $\mathrm{CV}$ of $\mathrm{TBACl}(50 \mathrm{mM})$ vs. $\mathrm{Fc} / \mathrm{Fc}^{+}$on glassy carbon electrode in $\mathrm{H}$-IL (blue trace) at $40^{\circ} \mathrm{C}, \mathrm{Me}-\mathrm{IL}$ (green trace) at $40^{\circ} \mathrm{C}$, and I-IL (red trace) at $60^{\circ} \mathrm{C} . \nu=0.1 \mathrm{~V} \mathrm{~s}^{-1}$. 
Table 4 Table of oxidative peak potential $E_{\mathrm{pOx}}$ and potential shift $\Delta E_{\mathrm{pOx}}$ for various Lewis bases TBAX (with $\mathrm{X}=\mathrm{Cl}, \mathrm{Br}, \mathrm{I}, \mathrm{NO}{ }_{3}$ and $p-\mathrm{NO}_{2} \mathrm{C}_{6} \mathrm{H}_{4} \mathrm{O}$ ) in Me-IL, H-IL or I-IL

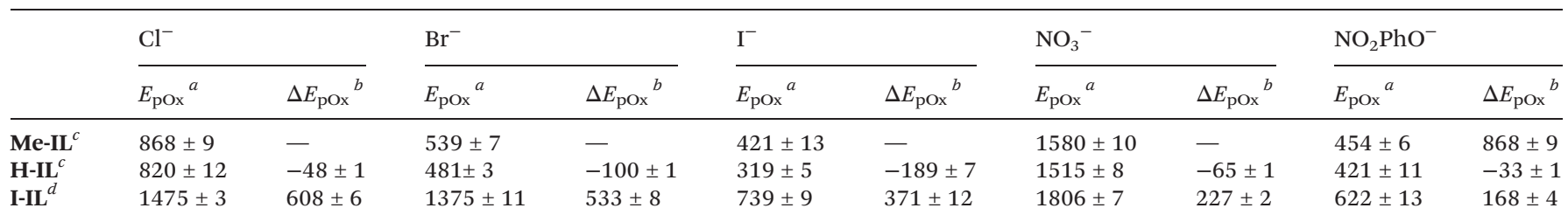

${ }^{a}$ In mV. ${ }^{b} \Delta E_{\mathrm{pOx}}=E_{\mathrm{pOx}}($ I-IL or H-IL $)-E_{\mathrm{pOx}}($ Me-IL $)$ in mV. ${ }^{c}$ At $40{ }^{\circ} \mathrm{C} .{ }^{d}$ At $60{ }^{\circ} \mathrm{C}$.

and Fig. S31 and $\mathrm{S} 32 \dagger)$. These potential shifts are in agreement with the order of decreasing basicity ranging from $\mathrm{Cl}^{-}$to $\mathrm{Br}^{-}$ then $\mathrm{I}^{-}$.

Most interestingly even weak XB acceptors such as phenolate and nitrate ions could be detected in the ILs. As expected, the variation is smaller compare to chloride but still significant with I-IL $\Delta E_{\mathrm{pOx}}\left(\mathrm{NO}_{3}{ }^{-}\right)=227 \mathrm{mV}$ and $\Delta E_{\mathrm{pOx}}\left(\mathrm{NO}_{2}-\mathrm{PhO}^{-}\right)=$ $168 \mathrm{mV}$, respectively (Fig. S32 and S33†).

Fig. 6 summarizes the variation of the oxidation potential of the respective anions depending on the employed ILs. I-IL showed the strongest impact certainly due to its strong XBdonor properties. The effect of $\mathbf{H}-\mathbf{I L}$ and $\mathbf{M e - I L}$ is more difficult to explain. As mentioned above, recent publications in the literature ${ }^{11 a, 22,28}$ highlighted the observation that methylation on $\mathrm{C} 2$ of the imidazolium ILs leads to unexpected changes of the respective physical properties due to the decrease of $\mathrm{HB}$ and coulombic attraction interactions. However, there are not sufficient elements to fully understand this phenomenon.

In order to confirm our data, we have performed a titration experiment and recorded CVs of chloride in pure Me-IL (green trace in Fig. 7) and then increased the concentration of I-IL (red trace in Fig. 7). Even upon the addition of $0.5 \mathrm{wt} \%$ of I-IL, the chloride oxidation potential shifted towards more positive values from 0.87 to $1.27 \mathrm{~V}$. This significant shift is consistent

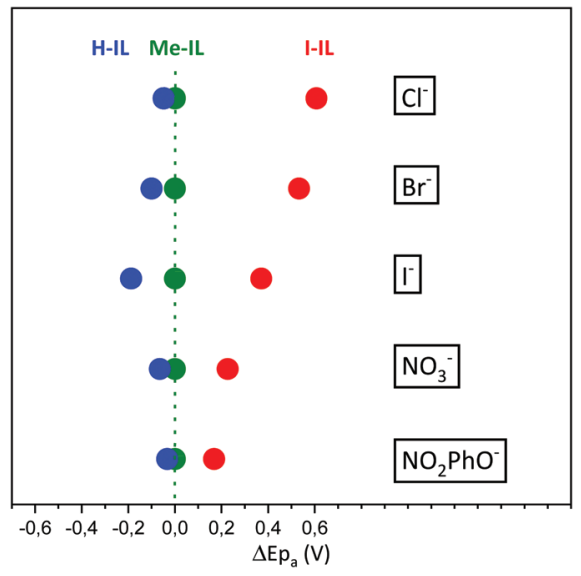

Fig. 6 Potential shift $\Delta E_{\mathrm{pOx}}$ for various Lewis base in H-IL and I-IL vs. Me-IL.

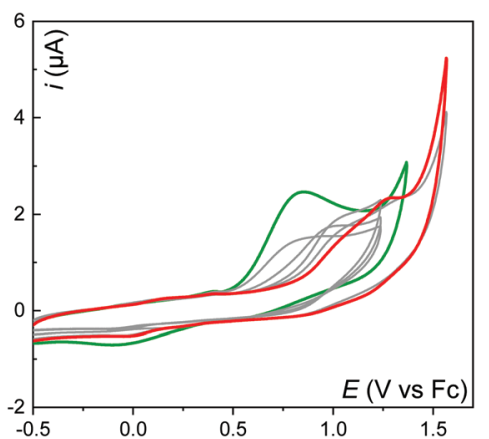

Fig. $7 \mathrm{CV}$ of TBACl $(10 \mathrm{mM})$ vs. $\mathrm{Fc} / \mathrm{Fc}^{+}$in pure $\mathrm{Me}-\mathrm{IL}$ (green trace) and with increasing concentration of $\mathrm{I}-\mathrm{Il}$ from $0.75,1.5,5$ to 15 equiv. (grey traces) and 50 equiv. (red trace). $40^{\circ} \mathrm{C} ; \nu=0.1 \mathrm{~V} \mathrm{~s}^{-1}$.

with a stabilization of chloride by I-IL via charge-assisted noncovalent XB interactions. To the best of our knowledge, it is the first time that anionic LB has been engaged through anodic oxidation to the formation of a XB complex.

\section{Conclusions}

A iodo-imidazolium based ionic liquid was synthesized and compared to the hydrogenated and methylated derivatives. All three ILs were fully characterised. X-ray diffraction analysis showed the formation of XB between I-IL and halides in the solid state. NMR titration experiments confirmed the relevance of $\mathrm{XB}$ as a non-covalent interaction in solution compared to HB or even coulombic interactions. The respective binding constants were determined either by NMR or by electrochemical experiments. More interestingly, the electrochemical behaviour of various redox-active Lewis base anions was investigated in the three ILs. The iodinated IL (I-IL) behaved as a strong XB-donor solvent and the formation of $\mathrm{XB}$ complexes with anions strongly impacts their electrochemical oxidation potentials and consequently the electrochemical window. Contrary to the results of NMR experiments, the impact of $\mathrm{HB}$ or coulombic interactions are not negligible in $\mathrm{CV}$ experiments. However, their effects are much less pronounced compared to those due to $\mathrm{XB}$ interactions. This information is crucial for the use of ILs as electrolytes for applications such as batteries and dye-sensitized solar cells. It also highlights 
once again the relevance of halogen bonding for supramolecular interactions in complex liquid media.

\section{Experimental section}

\section{Chemicals}

All reactions were performed under exclusion of air and water using oven dried flasks, dry solvents, and argon gas, unless otherwise noted. Small volumes for reactions were transferred using plastic NORMJECT syringes and BRAUN Luer cannulas. Exact volumetric manipulations were carried out with the aid of Eppendorf Micropipettes, for volumes between $0.1 \mu \mathrm{L}$ and $1 \mathrm{~mL}$. Thin layer chromatography (TLC) was performed on Merck TLC aluminium sheets (silica gel 60, F254) and column chromatography with silica gel (grain size $0.04-0.063 \mathrm{~cm}$, Macherey-Nagel Si60) at atmospheric pressure.

Chemicals were bought from TCI, Fluka and Sigma Aldrich. Tetrabutylammonium (TCI) salts (chloride (>98\%), bromide $(>99 \%)$, iodide (>99\%), nitrate (98\%), nitrophenoxide (>98\%)) were previously dried under vacuum before each used. 1-Ethyl3-methylimidazolium ethyl sulfate (Sigma Aldrich) was purified on charcoal. 1-Ethyl-2,3-methylimidazolium methyl sulfate was bought from Fluka. Methylene chloride (DCM), methanol (MeOH), tetrahydrofuran (THF) and petrol ether (PE) (60-80) were bought in technical grade quality and distilled prior to further use. Dimethyl formamide (DMF) and Acetonitrile (ACN) were bought in peptide grade quality, distilled, and dried twice over $3 \AA$ molecular sieves. $n$-Buthyllithium at $1.6 \mathrm{M}$ in hexane (Sigma Aldrich), methyltriflate (TCI) fresh bottles were opened, the bottles closed under argon and stored in the fridge. Bis(trifluoromethane)sulfonimide lithium salt (TCI) bottles were stored under vacuum. Deuterated solvents were obtained from Eurisotop (acetonitrile- $\mathrm{d}_{3}$, DMSO-d $\mathrm{d}_{6}$.

\section{Materials and methods}

NMR spectra were recorded on the following Brucker devices: DRX-400 (400 MHz). Shifts are given in parts per million (ppm). The generated data was analyzed with TopSpin, MestReNova 6 and Bindfit.

Melting points were determined on a Büchi Melting point M565 device and are reported uncorrected.

Single crystals structure was analyzed using a Bruker APEX-II with graphite monochromator, $\mathrm{Cu} \mathrm{K}_{\alpha}$ radiation from a microfocus sealed tube. The structure was solved using the Olex2 software package in combination with ShelXL and ShelXT. Tables for the publication were generated using a modified version of Ciftab. Pictures of the structures were generated with Diamond 4.

Cyclic voltammetry experiments were performed using a Metrohm AUTOLAB instrument for classical electrochemical. The measurements were performed in a thermostated onecompartment three electrodes cell containing. A mechanically polished glassy carbon disk electrode (carbon rod of $1.6 \mathrm{~mm}$ or $3 \mathrm{~mm}$ diameter embedded in an insoluble polymer matrix,
CHI Instruments. Inc., USA) was used as working electrode and a platinum wire as auxiliary electrode. A salt bridge containing the electrolyte was used to connect the electrochemical cell with a saturated calomel reference electrode (SCE) for experiments in organic solvent. A reference electrode of activated carbon (AC) was used for experiments in ionic liquids with ferrocene or decamethylferrocene as intern reference. Electrolyte and solvent were put into the electrochemical cell equipped with the working, auxiliary and reference electrode under anhydrous argon atmosphere. The solvents were degassed for a few minutes prior to the experiment. After taking a background scan, a solution containing the salt was added, the cyclic voltammogram and square wave cyclic voltammogram were recorded.

The titration experiments were performed by adding increasing amounts of a $1 \mathrm{M}$ TBAX stock solution to the IL sample, where $\mathrm{X}$ was the anion under investigation. The stock solutions were prepared using the IL being studied as the solvent. A $500 \mu \mathrm{L}$ aliquot of IL was placed in the electrochemical cell which was equipped with the working, auxiliary and reference electrodes. The cell was kept under an anhydrous argon atmosphere and at a constant temperature. The ILs were degassed for a few minutes and a blank CV recorded before starting the titration.

\section{Conflicts of interest}

There are no conflicts to declare.

\section{Acknowledgements}

The work was supported by the Laboratoire d'Electrochimie Moléculaire (UMR 7591 CNRS - Université de Paris). We thank Régis Guillot (ICMMO, Université Paris-Saclay) for the XRD analysis and Alexandra Pastor (LEM, Université de Paris) for her help in organic synthesis.

\section{Notes and references}

1 (a) G. Berger, J. Soubhye and F. Meyer, Polym. Chem., 2015, 6, 3559; (b) M. R. Scholfield, C. M. Vander Zanden, M. Carter and P. S. Ho, Protein Sci., 2013, 22, 139; (c) M. H. Kolar and O. Tabarrini, J. Med. Chem., 2017, 60, 8681; (d) R. L. Sutar and S. M. Huber, ACS Catal., 2019, 9, 9622.

2 (a) G. Cavallo, P. Metrangolo, R. Milani, T. Pilati, A. Priimagi, G. Resnati and G. Terraneo, Chem. Rev., 2016, 116, 2478; (b) G. Berger, P. Frangville and F. Meyer, Chem. Commun., 2020, 56, 4970.

3 G. R. Desiraju, P. S. Ho, L. Kloo, A. C. Legon, R. Marquardt, P. Metrangolo, P. Politzer, G. Resnati and K. Rissanen, Pure Appl. Chem., 2013, 85, 1711.

4 (a) S. Groni, T. Maby-Raud, C. Fave, M. Branca and B. Schöllhorn, Chem. Commun., 2014, 50, 14616; (b) R. Oliveira, S. Groni, C. Fave, M. Branca, F. Mavré, 
D. Lorcy, M. Fourmigué and B. Schöllhorn, Phys. Chem. Chem. Phys., 2015, 45, 19053; (c) E. Engelage, H. Hijazi, M. Gartmann, L. M. Chamoreau, B. Schöllhorn, S. Huber and C. Fave, Phys. Chem. Chem. Phys., 2021, 23, 4334; (d) J. Y. C. Lim, M. J. Cunningham, J. J. Davis and P. D. Beer, Chem. Commun., 2015, 51, 14640; (e) J. Y. C. Lim and P. D. Beer, Eur. J. Inorg. Chem., 2017, 220.

5 (a) H. Hijazi, A. Vacher, S. Groni, D. Lorcy, E. Levillain, B. Schöllhorn and C. Fave, Chem. Commun., 2019, 55, 1983;

(b) R. Hein, A. Borissov, M. D. Smith, P. D. Beer and J. J. Davis, Chem. Commun., 2019, 55, 4849.

6 (a) C. Fave and B. Schöllhorn, Curr. Opin. Electrochem., 2019, 15, 89; (b) F. G. L. Parlane, C. Mustoe, C. W. Kellett, S. J. Simon, W. B. Swords, G. J. Meyer, P. Kennepohl and C. P. Berlinguette, Nat. Commun., 2017, 8, 1.

7 (a) J. L. Anderson, J. Ding, T. Welton and D. W. Armstrong, J. Am. Chem. Soc., 2002, 124, 14247; (b) M. Kosmulski, J. Gustafsson and J. B. Rosenholm, Thermochim. Acta, 2004, 412, 47.

8 (a) N. V. Plechkova and K. R. Seddon, Chem. Soc. Rev., 2008, 37, 123; (b) Y. Huang, G. Luo, M. Huang, J. Wu, Z. Lan, L. Fan and J. Lin, Chem. Rev., 2015, 115, 2136; (c) P. Wasserscheid and T. Welton, Ionic Liquids in Synthesis, Wiley-VCH Verlag GmbH \& Co. KGaA, Weinheim, 2002; (d) V. I. Pârvulescu and C. Hardacre, Chem. Rev., 2007, 107, 2615.

9 (a) P. Hapiot and C. Lagrost, Chem. Rev., 2008, 108, 2238;

(b) M. C. Buzzeo, R. G. Evans and R. G. Compton, ChemPhysChem, 2004, 5, 1106.

10 S. Lerch and T. Strassner, Chem. - Eur. J., 2019, 25, 16251.

11 (a) P. Bonhöte, A. P. Dias, N. Papageorgiou, K. Kalyanasundaram and M. Grätzel, Inorg. Chem., 1996, 35, 1168; (b) H. Tokuda, K. Hayamizu, K. Ishii, M. A. B. H. Susan and M. Watanabe, J. Phys. Chem. B, 2005, 109, 6103.

12 (a) G. Cavallo, G. Terraneo, A. Monfredini, M. Saccone, A. Priimagi, T. Pilati, G. Resnati, P. Metrangolo and D. W. Bruce, Angew. Chem., Int. Ed., 2016, 55, 6300; (b) P. Metrangolo, Y. Carcenac, M. Lahtinen, T. Pilati, K. Rissanen, A. Vij and G. Resnati, Science, 2009, 323, 1461; (c) L. Lodeiro, R. Contreras and R. Ormazábal-Toledo, J. Phys. Chem. B, 2018, 122, 7907; (d) D. Gaspard, K. R. Seddon, P. K. J. Robertson and H. Q. N. Gunaratne, Chem. Commun., 2019, 55, 9088; (e) H. Li, Y. Lu, W. Wu, Y. Liu, C. Peng, H. Liu and W. Zhu, Phys. Chem. Chem. Phys., 2013, 15, 4405.

13 C. M. Forsyth, D. R. MacFarlane, J. J. Golding, J. Huang, J. Sun and M. Forsyth, Chem. Mater., 2002, 14, 2103.
14 O. Fontaine, J. Ghilane, P. Martin, J. C. Lacroix and H. Randriamahazaka, Langmuir, 2010, 26, 18542.

15 S. Chakraborty, R. Dutta and P. Ghosh, Chem. Commun., 2015, 51, 14793.

16 J. M. Fraile, J. I. García, C. I. Herrerías, J. A. Mayoral, S. Gmough and M. Vaultier, Green Chem., 2004, 6, 93.

17 (a) M. Saito, N. Tsuji, Y. Kobayashi and Y. Takemoto, Org. Lett., 2015, 17, 3000; (b) N. Tsuji, Y. Kobayashi and Y. Takemoto, Chem. Commun., 2014, 50, 13691; (c) D. von der Heiden, E. Detmar, R. Kuchta and M. Breugst, Synlett, 2018, 29, 1307.

18 A. J. Bard and L. R. Faulkner, Electrochemical methods fundamentals and applications, John Wiley \& Sons, Inc., 2nd edn, 2001.

19 (a) A. W. Taylor, P. Licence and A. P. Abbott, Phys. Chem. Chem. Phys., 2011, 13, 10147; (b) J. Fuller, R. T. Carlin and R. A. Osteryoung, J. Electrochem. Soc., 1997, 144, 3881.

20 (a) K. R. J. Lovelock, A. Ejigu, S. F. Loh, S. Men, P. Licence and D. A. Walsh, Phys. Chem. Chem. Phys., 2011, 13, 10155; (b) C. O. Laoire, E. Plicha, M. Hendrickson, S. Mukerjee and K. M. Abraham, Electrochim. Acta, 2009, 54, 6560.

21 (a) T. Mukai and K. Nishikawa, RSC Adv., 2013, 3, 19952; (b) T. Mukai and K. Nishikawa, Solid State Sci., 2010, 12, 783.

22 P. Hunt, J. Phys. Chem. B, 2007, 11, 4844.

23 http://app.supramolecular.org/BindFit/.

24 (a) A. Brown and P. D. Beer, Chem. Commun., 2016, 52, 8645; (b) S. Chakraborty, R. Butta and P. Ghosh, Chem. Commun., 2015, 51, 14793.

25 M. Cametti, K. Raatikainen, P. Metrangolo, T. Pilati, G. Terraneo and G. Resnati, Org. Biomol. Chem., 2012, 10, 1329.

26 (a) F. Zapata, A. Caballero, N. G. White, T. D. W. Claridge, P. J. Costa, V. Feélix and P. D. Beer, J. Am. Chem. Soc., 2012, 134, 11533; (b) A. Bondi, J. Phys. Chem., 1964, 68, 441.

27 (a) S. Chakraborty, S. Maji, R. Ghosh, R. Jana, A. Datta and P. Ghosh, Chem. Commun., 2019, 55, 1506; (b) S. M. Walter, F. Kniep, L. Rout, F. P. Schmidtchen, E. Herdtweck and S. M. Huber, J. Am. Chem. Soc., 2012, 134, 8507; (c) K. Raatikainen, G. Cavallo, P. Metrangolo, G. Resnati, K. Rissanen and G. Terraneo, Cryst. Growth Des., 2013, 13, 871.

28 (a) K. Noack, P. S. Schulz, N. Paape, J. Kiefer, P. Wasserscheidb and A. Leipertza, Phys. Chem. Chem. Phys., 2010, 12, 14153; (b) Y. Zhang and E. J. Maginn, Phys. Chem. Chem. Phys., 2012, 14, 12157. 